\title{
Esporulação in vitro e inoculação de Exserohilum turcicum em milho
}

\author{
Juliane Nicolodi Camera ${ }^{1} \oplus$, Jana Koefender ${ }^{1} \oplus$, Diego Pascoal Golle ${ }^{1} \mathbb{\oplus}$, Rafael Pivotto Bortolotto ${ }^{1} \mathbb{C}^{\circ}$

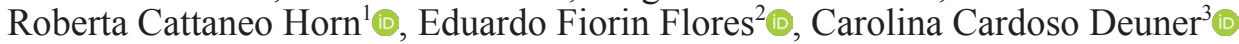

${ }^{1}$ Universidade de Cruz Alta. Centro de Ciências da Saúde e Agrárias/Mestrado Profissional em Desenvolvimento Rural. Cruz Alta, RS. Brasil. ${ }^{2}$ Engenheiro agrônomo autônomo. ${ }^{3}$ Universidade de Passo Fundo. Faculdade de Agronomia e Medicina Veterinária, Passo Fundo, RS. Brasil Autor para correspondência: Juliane Nicolodi Camera (ju_camera@yahoo.com.br)

Data de chegada: 02/07/2018. Aceito para publicação em: 05/02/2019.

$10.1590 / 0100-5405 / 191312$

\section{RESUMO}

Camera, J.N.; Koefender, J.; Golle, D.P.; Bortolotto, R.P.; Horn, R.C.; Flores, E.F.; Deuner, C.C.Esporulação in vitro e inoculação de Exserohilum turcicum em milho. Summa Phytopathologica, v.45, n.3, p.308-312, 2019.

A helmintosporiose está entre as principais doenças da cultura do milho. Realizou-se dois ensaios com os objetivos de avaliar a esporulação do fungo diferentes meios de cultura, métodos de inoculação e concentrações de inóculo para Exserohilum turcicum. Para a esporulação em diferentes meios de cultura, testou-se seis diferentes substratos: batata sacarose ágar (BSA), extrato de folha de milho (FM), potato dextrose ágar (PDA), suco V8 ágar (V8), lactose caseína hidrolisada ágar (LCHA) e meio semi-seletivo De Rossi e Reis (DRR) submetidos a dois regimes luminosos, fotoperíodo de 12 e escuro contínuo. E no segundo ensaio avaliou-se dois métodos de inoculação: a aspersão e a deposição do inóoculo no cartucho das plântulas, sendo testadas as concentrações de $5 \times 10^{3}, 10 \times 10^{3}, 15 \times 10^{3}$
$20 \times 10^{3}, 25 \times 10^{3}$ conídios $/ \mathrm{mL}$, e para o segundo foram depositados $0,5 \mathrm{~mL}$ na concentração de $20 \times 10^{3}$ conídios/mL nos cartuchos. Para ambos os métodos a inoculação foi feita no estádio V4 (quarta folha expandida, apresentando colar, lígula e aurículas visíveis), e mantidos em câmara úmida por 24 horas na temperatura de $25{ }^{\circ} \mathrm{C}$. Quinze dias após a inoculação, avaliou-se a severidade estimada e a área da lesão. O delineamento experimental foi inteiramente casualizado com quatro repetições e os dados obtidos foram submetidos à análise de variância e de regressão. $\mathrm{O}$ maior número de conídios. $\mathrm{cm}^{-2}$ foi obtido no meio DRR, independente do regime luminoso. O método de aspersão mostrou-se eficaz nas concentrações de $15 \times 10^{3}, 20 \times 10^{3} \mathrm{e}$ $25 \times 10^{3}$ conídios $/ \mathrm{mL}$

Palavras-chave: concentração de inóculo, helmintosporiose, Helminthospooium turcicum, meio de cultura, Zea mays.

\begin{abstract}
Camera, J.N.; Koefender, J.; Golle, D.P.; Bortolotto, R.P.; Horn, R.C.; Flores, E.F.; Deuner, C.C. In vitro sporulation and inoculation of Exserohilum turcicum in corn. Summa Phytopathologica, v.45, n.3, p.308-312, 2019.

Helminthosporiosis is among the major corn diseases. Two experiments were carried out with the aim of evaluating fungal sporulation in different culture media, inoculation methods and inoculum concentrations for Exserohilum turcicum. For sporulation in different culture media, six different substrata were tested: potato sucrose agar (BSA), maize leaf extract (FM), potato dextrose agar (PDA), V8 juice agar (V8), lactose casein hydrolysate agar (LCHA) and semi-selective medium De Rossi and Reis (DRR) subjected to two light regimes, 12 hours photoperiod and continuous dark. In the second assay, two inoculation methods were evaluated: spray and deposition of the inoculum in the seedling cartridge, testing the concentrations of $5 \times 10^{3}, 10 \times 10^{3}, 15 \times 10^{3} 20 \times 10^{3}, 25 \times 10^{3}$

conidia / $\mathrm{mL}$, and in the second one, $0.5 \mathrm{~mL}$ at the concentration of $20 \times 10^{3}$ conidia/mL were deposited in the cartridges. For both methods, inoculation was done in stage V4 (fourth expanded leaf, showing collar, ligule and visible auricles) and kept in a humid chamber for 24 hours at the temperature of $25{ }^{\circ} \mathrm{C}$. Fifteen days after inoculation, the estimated severity and the lesion area were evaluated. The experimental design was completely randomized with four replicates, and data were subjected to analysis of variance and regression. The highest number of conidia. $\mathrm{cm}^{-2}$ was obtained in the DRR medium, independent of the light regime. The spray method was effective at the concentrations of $15 \times 10^{3}, 20 \times 10^{3}$ and $25 \times 10^{3}$ conidia $/ \mathrm{mL}$.
\end{abstract}

Keywords: inoculum concentration, helminthosporiosis, Helminthospooium turcicum, culture medium, Zea mays.

O milho (Zea mays L.) é uma das culturas mais importantes para a economia brasileira, sendo a segunda cultura com maior produção de grãos no território nacional e com grande participação nas exportações. O Brasil é o terceiro maior produtor mundial de milho (17), concentrando a maior parte da produção na segunda safra (5), denominada de safrinha.

Dentre as doenças ocorrentes na cultura do milho, destaca-se a helmintosporiose, que tem como agente causal Exserohilum turcicum (Pass.) K. J. Leonard \& E. G. Suggs.. A esporulação de fitopatógenos é de extrema importância na condução de trabalhos de pesquisas, com relação ao regime luminoso, Teixeira et al. (15), mencionam que a radiação luminosa pode induzir, inibir ou ter efeito neutro sobre o crescimento e a esporulação dos fungos. A luz estimula a reprodução assexual e sexual na maioria dos fungos, e seu efeito está intimamente 
relacionado com a nutrição e com a temperatura. A composição do meio também é um fator importante na esporulação, quando um fungo cresce bem em um substrato e não em outro, acredita-se que metabólitos específicos estejam envolvidos (12).

Em pesquisa, rotineiramente utiliza-se inoculação artificial de fungos para diversos estudos, principalmente a reação de cultivares, porém para isso primeiramente é necessário determinar a concentração do inóculo de um patógeno que permita obter sintomas da doença que seja possível de avaliar e fácil de reproduzir (10). Diversos trabalhos já foram desenvolvidos com essa finalidade em vários patossistemas $(4,2)$, porém até o momento não se encontrou trabalhos na literatura testando concentrações de inóculo para E. turcicum.

Um dos grandes problemas encontrados para pesquisas em casade-vegetação com E. turcicum em milho é o tamanho das plantas de milho, o número de placas com esporulação intensa e a dificuldade de conseguir uma inoculação uniforme quando comparados com trabalhos de inoculação desenvolvidos para patógenos em outras culturas. Em relação a inoculação estudos mostram a inoculação apenas no cartucho, porém devido a concentração de inóculo no mesmo local da planta, as lesões formadas acabam coalescendo e interferindo nas avaliações.

Assim, este trabalho teve como objetivos (i) quantificar a esporulação de E. turcicum em diferentes meios de cultura, submetidos a (ii) dois regimes luminosos, avaliar (iii) dois métodos de inoculação e concentrações de inóculo de E. turcicum em milho.

\section{MATERIAL E MÉTODOS}

Esporulação de Exserohilum turcicum. O trabalho foi realizado no Laboratório de Fitopatologia e em câmara climatizada de crescimento da Faculdade de Agronomia e Medicina Veterinária da Universidade de Passo Fundo, Passo Fundo/RS.

Folhas com sintomas da helmintosporiose do milho foram recolhidas no campo, no município de Passo Fundo - RS. Discos das lesões de 9,0 mm de diâmetro foram cortados e desinfestados, e posteriormente imersos em álcool $96 \%$ por um minuto, em hipoclorito de sódio $1 \%$ por três minutos e enxaguados em água destilada e esterilizada. Após a desinfestação, foram distribuídos em caixas de acrílico tipo gerbox de poliestireno cristal ( $11 \times 11$ x 3,5 cm de altura). O material foi incubado em câmara de crescimento com temperatura de $25^{ \pm} 2^{\circ} \mathrm{C}$ e fotoperíodo de 12 horas. Após a esporulação do fungo, procedeu-se o isolamento monospórico (1).

Os tratamentos constaram de seis meios de cultura:

(1) Meio semi-seletivo de De Rossi \& Reis - DRR (em Erlemeyer de $2000 \mathrm{~mL}$ foram adicionados i) caseína hidrolisada $3 \mathrm{~g} / \mathrm{L}$, ii) ágar $10 \mathrm{~g} /$, iii) lactose $37,5 \mathrm{~g} / \mathrm{L}$, iv) $\mathrm{MgSO}_{4} .7 \mathrm{H}_{2} 00,5 \mathrm{~g} / \mathrm{L}$, v) $\mathrm{ZnSO}_{4} \cdot 7 \mathrm{H}_{2} 0$ $0,43 \mathrm{~g} / \mathrm{L}$, vi) $\mathrm{MnSO}_{4} \cdot 4 \mathrm{H}_{2} \mathrm{O} 0,2 \mathrm{~g} / \mathrm{L}$, vii) $\mathrm{Fe}\left(\mathrm{NO}_{3}\right) 3.9 \mathrm{H}_{2} \mathrm{O} 0,72 \mathrm{~g} / \mathrm{L}$, num volume final de $1000 \mathrm{~mL}$, após a diluição fez-se a correção do $\mathrm{pH}$, para 6 , adicionou-se após a autoclavagem do meio carbendazim $60 \mathrm{mg} / \mathrm{L}$ , captana $30 \mathrm{mg} / \mathrm{L}$ ).

(2) Batata sacarose ágar-BSA: (extrato de $200 \mathrm{~g}$ de batata, $20 \mathrm{~g}$ de dextrose e $16 \mathrm{~g}$ de ágar e água até completar o volume de $1000 \mathrm{~mL}$ ) (1).

(3) Suco V8 ágar: (200 mL de suco de vegetais V8 "Campbell Soup Co."; $16 \mathrm{~g}$ de agar; 3,2 g de CaCO3 e $800 \mathrm{~mL}$ de água destilada) (16).

(4) Lactose caseína hidrolisada ágar - LCHA em Erlemeyer de 2000 $\mathrm{mL}$ foram adicionados i) caseína hidrolisada $3 \mathrm{~g} / \mathrm{L}$, ii) ágar $10 \mathrm{~g} /$, iii) lactose $37,5 \mathrm{~g} / \mathrm{L}$, iv) $\mathrm{MgSO}_{4} .7 \mathrm{H}_{2} 00,5 \mathrm{~g} / \mathrm{L}$, v) $\mathrm{ZnSO}_{4} .7 \mathrm{H}_{2} 00,43 \mathrm{~g} / \mathrm{L}$, vi) $\mathrm{MnSO}_{4} \cdot 4 \mathrm{H}_{2} \mathrm{O} 0,2 \mathrm{~g} / \mathrm{L}$, vii) $\mathrm{Fe}\left(\mathrm{NO}_{3}\right) 3.9 \mathrm{H}_{2} \mathrm{O} 0,72 \mathrm{~g} / \mathrm{L}$, num volume final de $1000 \mathrm{~mL}$, após a diluição fez-se a correção do $\mathrm{pH}$, para 6 (16).
(5) Potato dextrose ágar - PDA, produto de marca comercial Acumédia : (39 g do produto) (1)

6) Extrato de folha de milho - FM (1): (extrato de $80 \mathrm{~g}$ de folha de milho picada e levada ao fogo até levantar fervura, $16 \mathrm{~g}$ de ágar e água até completar $1000 \mathrm{~mL}$ );

Os meios de cultura foram posteriormente autoclavados a 121 ${ }^{\circ} \mathrm{C}$ por 20 minutos e vertidos assepticamente em caixas de Petri de polietileno $(60 \times 15 \mathrm{~mm})$. Preparou-se oito caixas para cada um dos meios de cultura, sendo que no centro de cada caixa, colocou-se um disco de micélio de 4,68 $\mathrm{mm}$ de diâmetro do fungo crescido por 25 dias em meio de cultura BSA (16), proveniente do isolamento monospórico. Em seguida, quatro caixas de cada meio de cultura foram submetidas ao fotoperíodo de 12 horas e ao escuro contínuo. As placas foram distribuídas ao acaso na câmara de crescimento com lâmpadas fluorescentes OSRAM ${ }^{\circledR}$ Universal, 40 watts, a $25^{\circ} \mathrm{C}$ por vinte e cinco dias. Decorrido esse tempo, procedeu-se a quantificação da esporulação, sendo que para isso, foram adicionados $5 \mathrm{~mL}$ de água destilada na caixa de Petri e com o auxílio de um pincel, os conídios foram removidos. A partir da suspensão de esporos, coletou-se $1 \mathrm{~mL}$, e em seguida contou-se o número de conídios em hemacitômetro tipo Neubauer (1) e calculou-se o número de conídios. $\mathrm{cm}^{-2}$, com base na área da placa coberta com o meio de cultura e número de conídios no volume de água utilizado na sua remoção.

$\mathrm{O}$ delineamento experimental foi inteiramente casualizado, com arranjo fatorial duplo $6 \times 2$ (meios de cultura $\times$ regimes luminosos) com quatro repetições. O número de conídios. $\mathrm{cm}^{-2}$ foi submetido à análise da variância e ao teste Tukey $5 \%$ para a comparação de médias.

Métodos de inoculação e concentração de inóculo de Exserohilum turcicum

O ensaio foi executado no Laboratório de Fitopatologia e em casa de vegetação, na Faculdade de Agronomia e Medicina Veterinária da Universidade de Passo Fundo. Utilizou-se a cultivar híbrida Pioneer $\mathrm{P} 1630 \mathrm{H}$, já previamente descrito como altamente suscetível a helmintosporiose. A semeadura foi realizada em vaso com $10 \mathrm{Kg}$ de solo hortado, sendo esses mantidos em casa-de-vegetação.

O inóculo utilizado foi obtido a partir de folhas de milho procedentes do município de Passo Fundo-RS. Isolou-se o fungo de folhas com lesões da helmintosporiose. Para isso foram cortados fragmentos de $5 \mathrm{~mm}$ de folhas com sintomas e em seguida foram desinfestados numa solução aquosa de hipoclorito de sódio (1\%) por três minutos e lavados três vezes com água destilada esterilizada. Os fragmentos foram distribuídos em caixas de acrílico, tipo gerbox, contendo uma espuma de nylon e duas folhas sobrepostas de papel filtro, humedecidas com água destilada esterilizada, formando uma câmara húmida. As caixas foram mantidas num ambiente com temperatura de $25 \pm 2^{\circ} \mathrm{C}$ e fotoperíodo de 12 horas. Após cinco dias, com o auxílio de uma agulha histológica flambada, estruturas do fungo foram transferidas para caixas de Petri contendo meio de cultura LCH (Lactose Caseína Hidrolisada) (16) para o crescimento do mesmo.

Uma alíquota de $10 \mathrm{~mL}$ de água destilada esterilizada foi adicionada a caixa contendo colónia de E. turcicum e com auxílio de um pincel procedeu-se à remoção dos esporos da superfície. A suspensão foi vertida em frasco para coleta de amostras de $10 \mu \mathrm{L}$ para contagem do número de conídios. Uma amostra de $0,5 \mathrm{~mL}$ dessa suspensão foi espalhada sobre a superfície de meio de cultura ágar-água e incubada em câmara de crescimento por 8 horas, a $25 \pm 2{ }^{\circ} \mathrm{C}$, com luz. Decorrido esse período com auxílio de lupa e estilete, pequenas porções de meios contendo um esporo germinado foram transferidas para caixas contendo 
meio de cultura LCH e incubadas no escuro até o crescimento de colónias puras do fungo (1).

Após trinta dias, as colónias contendo o fungo esporulado em meio LCH, foram cobertas com água destilada esterilizada. Os conídios formados foram removidos com pincel. Avaliou-se dois métodos de inoculação, aspersão e deposição no cartucho das plântulas, sendo que para o primeiro foram testados as concentrações de $5 \times 10^{3}$, $10 \times 10^{3}, 15 \times 10^{3}, 20 \times 10^{3}, 25 \times 10^{3}$ conídios/mL mais a testemunha pulverizada apenas com água, e para o segundo foram depositados 0,5 $\mathrm{mL}$ na concentração de $20 \times 10^{3}$ conídios $/ \mathrm{mL}$. Ambos os métodos foram inoculados no estádio V4 (quarta folha expandida, apresentando colar, lígula e aurículas visíveis) e mantidos em câmara húmida por 24 horas.

Quinze dias após a inoculação, avaliou-se a severidade estimada e a área de quatro lesões foram medidas quanto ao comprimento $(C)$ e largura (L) da área necrosada, com um paquímetro digital de precisão de

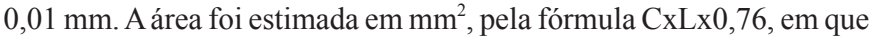
valor 0,76 corresponde ao fator de correção obtido pela comparação do produto de $\mathrm{C}$ x L com a área real medida em um integralizador digital de área foliar (Licor). O delineamento experimental foi completamente casualizados com quatro repetições. Os dados obtidos foram submetidos à análise de variância, sendo as médias comparadas pelo teste de SkottKnott, em nível de 5\% de probabilidade.

\section{RESULTADOS E DISCUSSÃO}

Esporulação de Exserohilum turcicum. Com relação ao regime luminoso, quando as culturas foram submetidas ao fotoperíodo de 12/12 $\mathrm{h}$, somente os meios V8 e LCHA foram estatisticamente inferiores na esporulação do fungo, os demais meios foram estatisticamente iguais sendo indiferentes para a presença ou ausência de luz (Tabela 1).

Para os meios de cultura, independente se foram submetidas ao fotoperíodo de $12 / 12 \mathrm{~h}$ ou ao escuro contínuo, o meio de cultura no qual ocorreu a maior esporulação do fungo foi o DRR, diferindo estatisticamente dos demais (Tabela 1). Para o fotoperíodo de 12/12 h, os meios BSA, PDA, FM, V8 e LCHA foram semelhantes entre si e apresentaram as menores esporulações, enquanto que para o escuro contínuo, os meios PDA e FM foram estatisticamente inferiores para esporulação do fungo (Tabela1).

Os resultados obtidos neste trabalho comprovam os resultados obtidos por De Rossi \& Reis (7), que utilizaram este fungo em sementes de milho inoculadas artificialmente, onde o meio DRR foi o mais sensível. Não foram encontrados na literatura outros trabalhos que relatem o uso deste meio de cultura.

Os dados também corroboram com Tuite (16) onde o meio LCHA induz a esporulação de E. turcicum, sendo esse meio utilizado rotineiramente em muitos patógenos $(11 ; 169,8)$, apesar de que na presente pesquisa o fungo não obteve a melhor esporulação, porém satisfatória. Da mesma forma Nakamura \& Gimenes-Fernandes (13), relataram a obtenção de conídios e conidióforos de E. turcicum em meio de cultura V8, semelhante ao encontrado neste trabalho.

Soares et al. (14) relataram em seus trabalhos que o meio de batata dextrose ágar (BDA) não conseguiu induzir a esporulação de todos os isolados de E. turcicum testados, o que se confirma neste ensaio.

\section{Métodos de inoculação e concentração de inóculo de Exserohilum turcicum}

Tanto para severidade como para área das lesões, a concentração de $20 \times 10^{3}$ inoculada pela deposição de $0,5 \mathrm{~mL}$ no cartucho, apresentou o maior valor diferindo estatisticamente das demais concentrações, porém as lesões coalesceram rapidamente não permitindo avaliar o progresso da doença no decorrer do tempo. Para a inoculação por aspersão nas concentrações de $15 \times 10^{3}, 20 \times 10^{3}$ e $25 \times 10^{3}$ conídios $/ \mathrm{mL}$, foi possível avaliar de forma precisa a intensidade da doença, podendo ser utilizada em trabalhos de pesquisas a concentração de $15 \times 10^{3}$ (Figura 1A). Quando utilizou-se concentrações menores no mesmo método de inoculação $\left(5 \times 10^{3}\right.$ e $\left.10 \times 10^{3}\right)$, não foi possível representar a epidemia, pois o número e área das lesões foi muito baixo, sendo que à medida que a concentração de inóculo aumenta as variáveis em estudo também aumentam (Figura $1 \mathrm{~A}$ e 1B).

Verificou-se que houve uma relação entre a concentração de inóculo e a intensidade de doença (severidade, área da lesão) pelo método de inoculação por aspersão, sendo que os dados mostram um aumento crescente da intensidade da doença com o aumento da concentração de inóculo do fungo, tendo sido obtido o nível mais elevado (ponto máximo) para a concentração de $25 \times 10^{3}$ conídios $/ \mathrm{mL}$ (Figura 2Ae 2B).

Vários métodos de inoculação são citados em trabalhos científicos com manchas foliares em milho, De Rossi et al. (7) utilizaram em seus trabalhos o método de inoculação por deposição de $0,5 \mathrm{~mL}$ do inóculo (5 x $10^{4}$ conídios $/ \mathrm{mL}$ ) no cartucho das plântulas no estádio V4, semelhante a esse com E. turcicum e obtiveram também resultados satisfatórios, conseguindo reproduzir a doença.

Tabela 1. Esporulação de Exserohilum turcicum em diferentes meios de cultura e regimes luminosos.

\begin{tabular}{|c|c|c|c|}
\hline Meios de cultura & \multicolumn{2}{|c|}{ Esporulação (conídios.cm²) } & Médias \\
\hline De Rossi e Reis & A $8359,2 a^{3}$ & A 8423,3 a & 8391,3 a \\
\hline Batata sacarose ágar & A $1356,4 \mathrm{~b}$ & A 1880,8 c & $1618,6 \mathrm{~b}$ \\
\hline Suco V8 ágar & B 848,8 bc & A 2266,5 c & $1557,7 \mathrm{~b}$ \\
\hline Potato dextrose agar & A 180,2 bc & A $41,2 \mathrm{~d}$ & $110,7 \mathrm{c}$ \\
\hline Extrato de folha de milho & A $0,00 \mathrm{c}$ & A $0,0 \mathrm{~d}$ & $0,0 \mathrm{c}$ \\
\hline Médias & $1825,8 \mathrm{~b}$ & $2790,4 \mathrm{a}$ & \\
\hline
\end{tabular}

CV (\%)

14,8

${ }^{1}$ Fotoperíodo: 12 horas de luz e 12 horas de escuro; ${ }^{2}$ Escuro contínuo; ${ }^{3}$ Médias seguidas por mesma letra minúscula na coluna e maiúscula na linha, não diferem entre si pelo teste de Tukey a $5 \%$ de probabilidade do erro. 


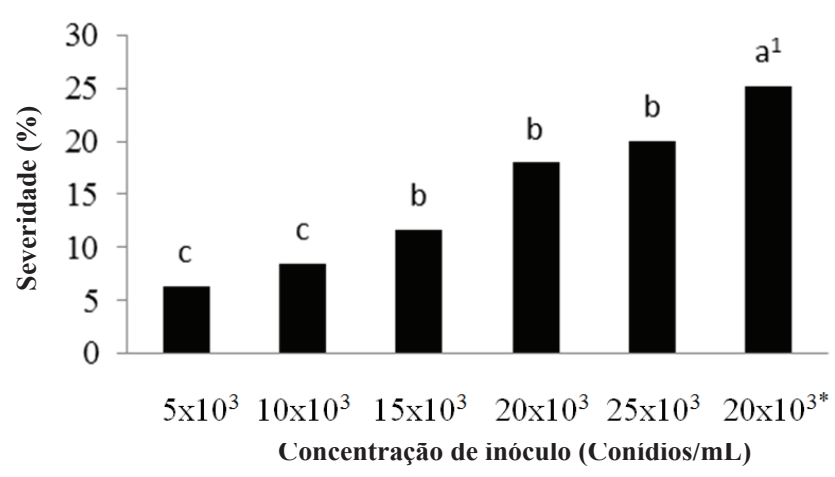

Figura 1 A. Efeito de diferentes concentrações de inóculo e o método de inoculação no cartucho do milho de Exserohilum turcicum sobre a severidade foliar no híbrido Pioneer P1630H. ${ }^{1}$ Médias seguidas de mesma letra não diferem pelo teste de Scott-knott a 5\%. *Inoculação por deposição de 0,5 mL no cartucho.

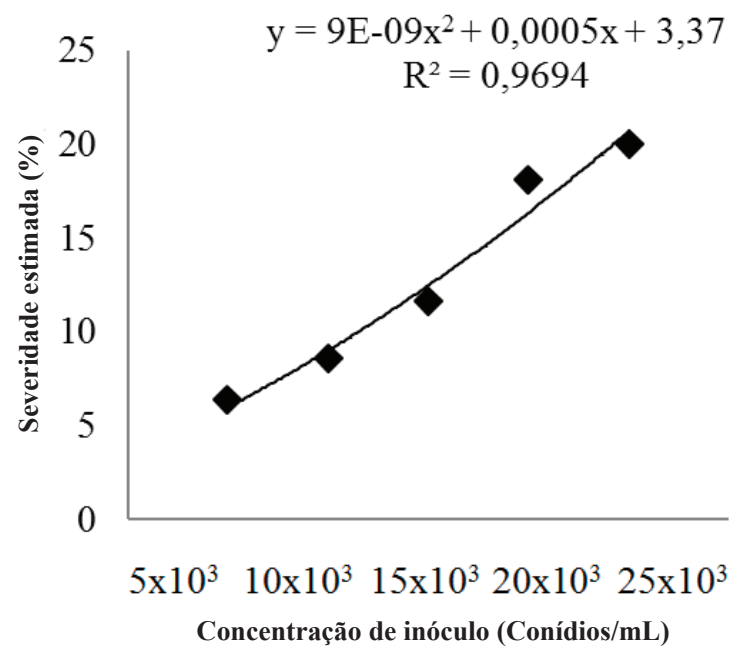

Figura 2 A. Relação entre aa concentração de inóculo de Exserohilum turcicum $e$ a severidade estimada no híbrido Pioneer P1630H.

Fernandes \& Balmer (8), em ensaios conduzidos para a verificação de resistência de genótipos utilizaram o método de inoculação no cartucho, porém na concentração de $5 \times 10^{3}$ conídios $/ \mathrm{mL}$, o que apresentou uma quantificação satisfatória da doença. Já em trabalhos conduzidos por Bleicher \& Balmer (3) utilizaram a concentração de $2,5 \times 10^{3}$ conídios $/ \mathrm{mL}$ e em outro trabalho conduzido pelos mesmos autores utilizaram a concentração de $1 \times 10^{3}$ conídios $/ \mathrm{mL}$ inoculadas no cartucho, sendo satisfatória. Já Cota et al. (6) com o método de inoculação por aspersão na concentração de $10^{4}$ conídios $/ \mathrm{mL}$.

A maior esporulação (conídios.cm ${ }^{-2}$ ) de E. turcicum é obtida no meio semi-seletivo De Rossi e Reis (DRR), independente do regime luminoso.

Nas condições de casa- de-vegetação onde o ensaio foi realizado a inoculação por aspersão resultou em intensidade semelhante a de inoculação nos cartucho.

A concentração de $15 \times 10^{3}$ conídios / $\mathrm{mL}$ inoculadas pelo método de aspersão gera intensidade que permite a avaliação de cultivares de milho a E. turcicum.

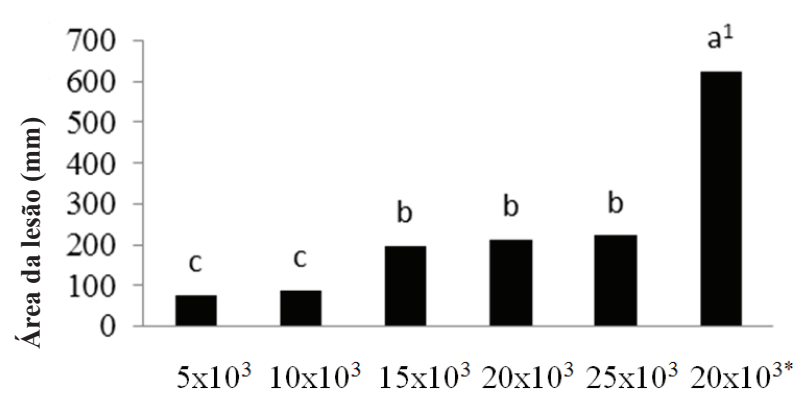

Concentração de inóculo (Conídios/mL)

Figura 1 B. Efeito de diferentes concentrações de inóculo e o método de inoculação no cartucho do milho de Exserohilum turcicum sobre a área da lesão $\left(\mathrm{mm}^{2}\right)$ no híbrido Pioneer P1630H. ${ }^{1}$ Médias seguidas de mesma letra não diferem pelo teste de Scott-knott a 5\%. *Inoculação por deposição de 0,5 mL no cartucho.

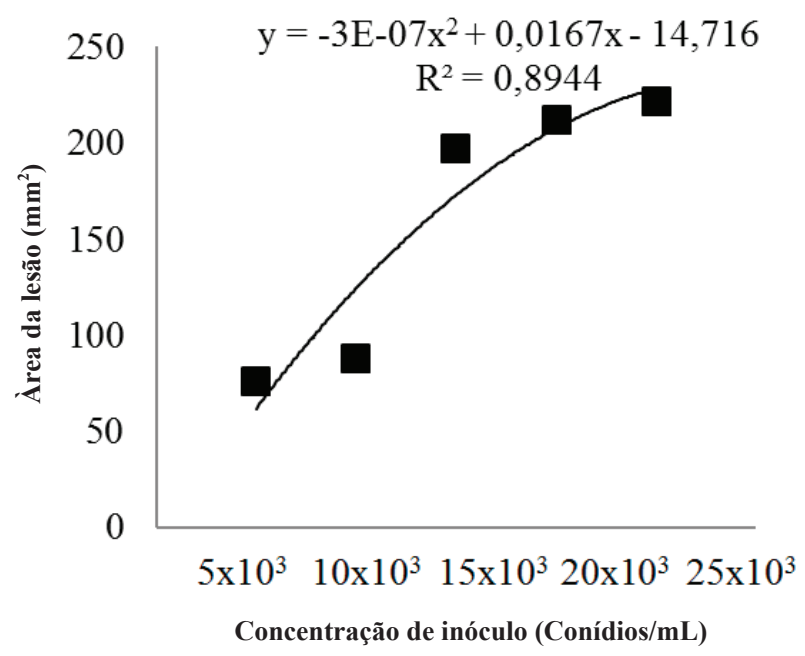

Figura 2 B. Relação entre a concentração de inóculo de Exserohilum turcicum e a área da lesão $\left(\mathbf{m m}^{2}\right)$ no híbrido Pioneer $\mathrm{P} 1630 \mathrm{H}$.

\section{REFERENCIAS}

1. Alfenas, A.C.; Mafia, R.G. Métodos em fitopatologia. Viçosa: Editora UFV, 2006. 382p.

2. Barba, J.T.; Reis, E.M.; Forcelini, C.A. Efeito do substrato na morfologia de conídios de Bipolaris sorokiniana e da densidade de inóculo na intensidade da mancha marrom em cevada. Fitopatologia Brasileira, Lavras, v.29, p.5-10, 2004. Disponível em: <http://www.scielo.br/pdf/\%0D/fb/v29n1/ a01v29n1.pdf $>$. Acesso em: 25 jul. 2016.

3. Bleicher, J.; Balmer, E. Armadilha para captura de conídios de Exserohilum turcicum, modelo Grimpa e relações entre parâmetros climáticos e captura de conídios. Summa Phytopathologica, Botucatu, v.19, p.118-123, 1993.

4. Camera, J.N.; Deuner, C.C.; Reis, E.M. Diferentes concentrações do inóculo de Cercospora sojina na intensidade da mancha foliar "olho-derã" em soja. Summa Phytopathologica, Botucatu, v.38, n.3, p.235-238, 2012. Disponível em: $<$ http://www.scielo.br/pdf/sp/v38n3/a10v38n3.pdf $>$. Acesso em: 23 jun. 2016.

5. Companhia Nacional de Abastecimento. Acompanhamento da safra brasileira de grãos, v. 3 - Safra 2015/16, n 5 - Quinto levantamento, fevereiro 2016. Brasília, 2016.. Acesso em: 11 jan. 2017.

6. Cota, L.V.; Costa, R.V.; Silva, D.D.; Parreira, D.F. Recomendação para o controle químico da helmintosporiose do sorgo (Exserohilum turcicum). Sete Lagoas: Embrapa Milho e Sorgo, 2010. (Circular Técnica, 149). Disponível em: <https://www.embrapa.br/busca-de-publicacoes/-/ 
publicacao/876528/recomendacao-para-o-controle-quimico-da-helmintosporiose-do-sorgo-exserohilum-turcicum>. Acesso em: 14 abr.2016.

7. De Rossi, R.L.; Reis, E.M. Semi-selective culture medium for Exserohilum turcicum isolation from corn seeds. Summa Phytopathologica, Botucatu, v.40, n.2, p.163-167, 2014. Disponível em: <http://www.scielo.br/pdf/sp/ v40n2/v40n2a09.pdf>. Acesso em: 13 jan.2015.

8. Fernandes, M.C.A.; Balmer, E. Variabilidade de isolados de Exserohilum turcicum em cultivares de milho (Zea mays). Revista de Ciências da Vida, Sete Lagoas, v.22, n.1, p.1-5, 2002.

9. Fernandes, F.T.; Balmer, E. Situação das doenças de milho no Brasil. Informe Agropecuário, Belo Horizonte, v.14, n.165, p.35-37, 1990.

10. Fernandes, C.D.; Del Peloso, M.C.; Maffia, L.A.; Do Valle, F.X.R.; Zamboa lim, L. Influência da concentração de inóculo de Cercospora coffeicola e do período de molhamento foliar na intensidade da cercosporiose do cafeeiro. Fitopatologia Brasileira, Lavras, v.16, p.39-43, 1991.

11. Malca, I.; Ullstrup, A.J. Effects of carbon and nitrogen nutrition on growth and sporulation of two species fo Helminthosporium. Bulletin of the Torrey Botanical Club, New York City, v.89, p.240-249, 1962.
12. Menezes, M.; Silva-Hanlin, D.M.W. Guia prático para fungos fitopatogênicos. Recife: UFRPE, 1997. 106p.

13. Nakamura, A.M.; Gimenes-Fernandes, N. Obtenção de esporos de Bipolaris e de Exserohilum em meio de cultura. Summa Phytopathologica, Botucatu, v.19 p.38, 1993.

14. Soares, A.M.Q.; Fonseca, M.E.N.; Lopes, C.A. Caracterização cultural, grupos de compatibilidade e padrões isoenzimáticos de isolados de Exserohilum turcicum obtidos de milho (Zea mays). Fitopatologia Brasileira, Brasília, v.18 p.219-225, 1993.

15. TEIXEIRA, H.; CHITARRA, L. G.; ARIAS, S. M. S.; MACHADO, J. C. Efeito de diferentes fontes de luz no crescimento e esporulação in vitro de fungos fitopatogênicos. Ciência Agrotécnica, Lavras, v. 25, p. 1314 1320, 2001

16. Tuite, J. Plant pathological methods: fungi and bacterial. 5.ed. Minneapolis: Burgess Publishing Company, 1969. 239p.

17. White, D.G. Compendium of corn diseases. 3 th ed. St. Paul: American Phytopathological Society, 2000. 78p. 